\title{
PERCEPTION OF TEACHERS AND STUDENTS ABOUT TEACHING AND LEARNING IN THE PERIOD OF COVID-19 PANDEMIC
}

\author{
Osvaldo Silva1, Áurea Sousa ${ }^{2}$ \\ ${ }^{1}$ University of Azores, Faculty of Sciences and Technology, CICS.UAc/CICS.NOVA.UAC \\ (PORTUGAL) \\ ${ }^{2}$ University of Azores, Faculty of Sciences and Technology, CEEApIA (PORTUGAL)
}

\begin{abstract}
In the current period of Covid-19 pandemic crisis, there were very unexpected changes in the society, in general, and in the education system, in particular, with the quick change to distance learning and teaching. This situation took the educational community by surprise and, in particular, its main protagonists (students and teachers). The digital revolution poses new challenges, but it also provides renewed learning opportunities that make it possible to face the current situation. However, there are still social inequalities in access to computer equipment and internet.

This empirical study aims to investigate how teachers evaluated their performance in the context of distance learning and teaching, due to the current pandemic situation, in terms of pedagogical resources and instruments, teaching strategies and assessment of learning, as well as the students' perceptions about those topics. The sample was composed of 30 teachers and 960 students (at the level of the 10th year of schooling) of Portuguese secondary schools. Data, collected by questionnaire, were analyzed using Descriptive Statistics and Inferential Statistics (namely, the hypothesis test for the difference between two proportions). It was found that, in general, teachers expressed the most favorable opinions toward distance learning and teaching, comparatively to the students. On the other hand, students expressed a greater diversity of opinions, when compared to the teachers. The most dissonant opinions between the two parties were those referring to the items "Diversification of the resources used", "Diversification of the activities carried out", "Incentive to participate in activities and projects that contribute to learning" and "Carrying out activities involving other disciplines". The most similar opinions between students and teachers are related to the items "opportunities to participate in class activities" and "explanation of the evaluation criteria".
\end{abstract}

Keywords: Teaching and learning, Perception of teachers and students, period of Covid-19 pandemic.

\section{INTRODUCTION}

In the traditional teaching and learning environment, it has been recognized that students' motivation is related to their perception of teacher-student interaction, and that the role of teachers and factors in the classroom environment should be highlighted (e.g., [1]).

According to Wayne and Youngs (2003) [2], students' academic performance depends on the interaction they establish with the teachers they have throughout their schooling. To promote a profitable student learning, teachers should try to create an environment in the classroom, so that students acquire the required knowledge and skills in order to be successful [3]. Furthermore, what the teacher does in the classroom is the main factor that determines students' learning and success [4]. The classroom is the place of excellence to understand how the teaching and learning processes are interconnected and interact and how the evaluation provides information, to the student, about the evolution of their learning and, to the teacher, about the evolution of the learning of each of its students. Based on this information, the teacher can introduce the necessary and opportune adaptations in his (or her) teaching practice [5], in order to change concepts and practices that are too entrenched and difficult to replace [6].

Students' involvement in the assessment process develops awareness of their learning, the way they acquire it, and promotes their autonomy and their ability to reflect on their own actions so as to engage in a process of continuous learning. Moreover, knowing the evaluation criteria and the respective levels of performance helps students to self-regulate their learning and to know clearly what they want to learn and how they will be evaluated. The use of assessment instruments makes it possible to establish sources of information, both for the teacher and for the students. Teachers must collect data regarding the skills, preferences and difficulties of each student. As far as students are concerned, the 
instruments should provide information that helps them with reflection and self-regulation regarding their own learning processes. The collected data can give guidelines for future teaching activities, which provide new opportunities for students to learn.

Due to the COVID-19 crisis, teachers and students both find themselves in the situation where they felt obliged to embrace the digital academic experience in the online teaching-learning process. Teachers were forced to start teaching remotely within a short time span, even though most digital learning environments, and their support systems were not ready to work, leading to a heavy burden on teachers, who sometimes lack social-emotional competencies to cope with such circumstances [7].

According Song et al. (2004) [8], the students feel that lack of community, technical problems, and difficulties in understanding instructional goals are the major barriers for online learning. In a study developed by Parkes et al., 2014 [9], students were found to be poorly prepared for several e-learning competencies and academic-type competencies. The same authors also concluded that students were not sufficiently prepared for balancing their work, family, and social lives with their study lives in an online learning environment.

According to Smart and Cappel (2006, p. 202) [10]: "Although e-learning (and various blended approaches that integrate online components into traditional classes) continues to grow rapidly, it still remains at an early stage of development." Thereby, teachers need more understanding about the student's perceptions about pedagogical resources and instruments, teaching strategies, and assessment of learning. Besides, various researchers have shown that learning in an online environment requires a significant amount of discipline and self-motivation [11, 12].

Student engagement is crucial to academic performance (e.g., [13]). In fact, according to Husain et al. [14], "Student's feedback is an effective tool for teachers' evaluation (...). However, other sources of feedback may also be utilized for the overall assessment of a teacher."

Silva et al. [15] mention three important factors that influence the students' satisfaction, namely: teacher/tutor, technology, and interactivity. In fact, according to the same authors, the teacher is not only a facilitator of learning but also a motivator for the students. In the context of teaching-learning environment, the access to technology is one of the most important factors that influence the students' satisfaction [15].

In a very short period, teachers and students were faced with a sudden change from the classroom space to the functioning of distance learning. However, the majority of teachers maintained the criteria that, at the beginning of the year, were indicated to be taken into account in the evaluation of students. In this context, the present work aims to evaluate the perceptions of teachers and students of two Portuguese Secondary schools regarding teaching and learning, during the Covid-19 pandemic, in order to analyze the impacts resulting from this change in the teaching-learning process together of its main actors (teachers and students).

\section{METHODOLOGY}

The target population of this study was the students who attend the level of the 10th year of Secondary school and their teachers. The present study adopts a quantitative approach and the data were collected through a purpose-built questionnaire, aimed to teachers and students in two Portuguese secondary schools, at the end of the 3rd period of the 2019-2020 academic year, during the period of COVID-19 pandemic.

For data collection, a sample was selected using a cluster sampling strategy, which included classes according to the respective scientific areas of study and the geographic location of the schools, in order to portray, as best as possible, the situation in Portugal. Cluster sampling is typically used when it is not possible get information about the population as a whole, but we can get information about the clusters (in the present study, the secondary schools). Moreover, this type of sampling is often more economical or more practical than stratified sampling or simple random sampling (e.g., [16]). All participants signed an informed consent protocol, and the data confidentiality was assured.

The questionnaire focuses on teachers and students' perceptions about eleven items related with the teaching and learning, which were assessed using a 4-point Likert scale (1-never; 2-sometimes; 3often; 4-always).

The items "I use diverse resources" (R1) and "I use the school manual" (R2) give information about Resources and instruments used in the classroom. Strategies to support student learning are 
described by the items: "Encourage student participation" (E1), "Diversification of classroom activities" (E2), "Encourage student participation in project activities and work" (E3), "Clarification of doubts" (E4), and "I carry out activities / projects that involve other discipline (s)" (E5). The items "Evaluation criteria explained" (Av1), "It helps students to understand their difficulties and how to overcome them" (Av2), "Learning is assessed in different ways" (Av3), and "Use of students' self-assessment in order to make them reflect on their learning" (Av4) are included in the Learning assessment. It should be emphasized that the sentences concerning the items was adapted according to the respondent (teacher or student). The categories of responses 3 (often) or 4 (always) correspond to positive perceptions regarding the statements related to these items. The sample is composed of 30 teachers and 960 students of the 10th year of two Portuguese Secondary schools.

In the context of the present study (distance learning), we defined the following research question: Do students and teachers have different perceptions about the assessment of pedagogical resources and tools; teaching strategies; and the evaluation of learning?

Data analysis, within the scope of Exploratory Data Analysis and Inferential Statistics (namely, the hypothesis test for the difference between two proportions) were carried out, using the IBM SPSS Statistics (Version 25). In the present study, some algorithms of Ascendant Hierarchical Cluster Analysis (AHCA) of the eleven items was carried out, in order to obtain two different typologies of these items, one for teachers and another one for students. The AHCA was based on the Spearman's correlation coefficient and on three classical aggregation criteria, namely Single Linkage, Complete linkage, and Average Linkage between groups (e.g., [17]). Here, we only present the dendrograms provides by Average Linkage method, given the robustness of the clustering results.

\section{RESULTS}

The majority of teachers say that they always use resources and support instruments in class (R1_T) $(80 \%)$, and that they only use school textbooks (R2_T) a few times $(60 \%)$, as is shown in Figure 1. On the other hand, students' perceptions are less consensual than those of teachers concerning these two items (R1 and R2).

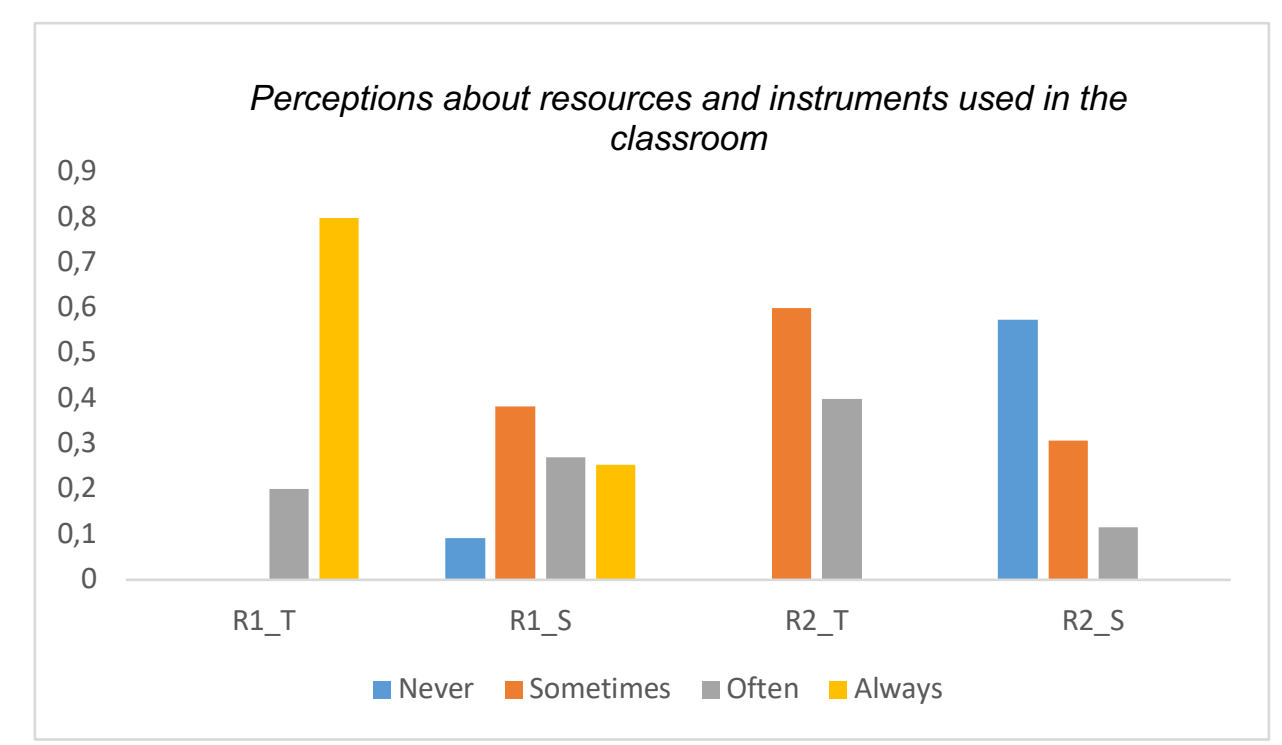

Figure 1. Perceptions of teachers and students about resources and instruments used in the classroom

With regard to the strategies used to support student learning, all teachers surveyed stated that they are always willing to clarify students' doubts (E4_T) and the majority $(80 \%)$ of them say that they always encourage student participation (E1_T). Still in this context, the teachers' perceptions are more positive, compared to those expressed by the students, since the uppermost proportion of their responses fall into the highest rated categories ("Often" and "Always"), as shown in Figure 2. 


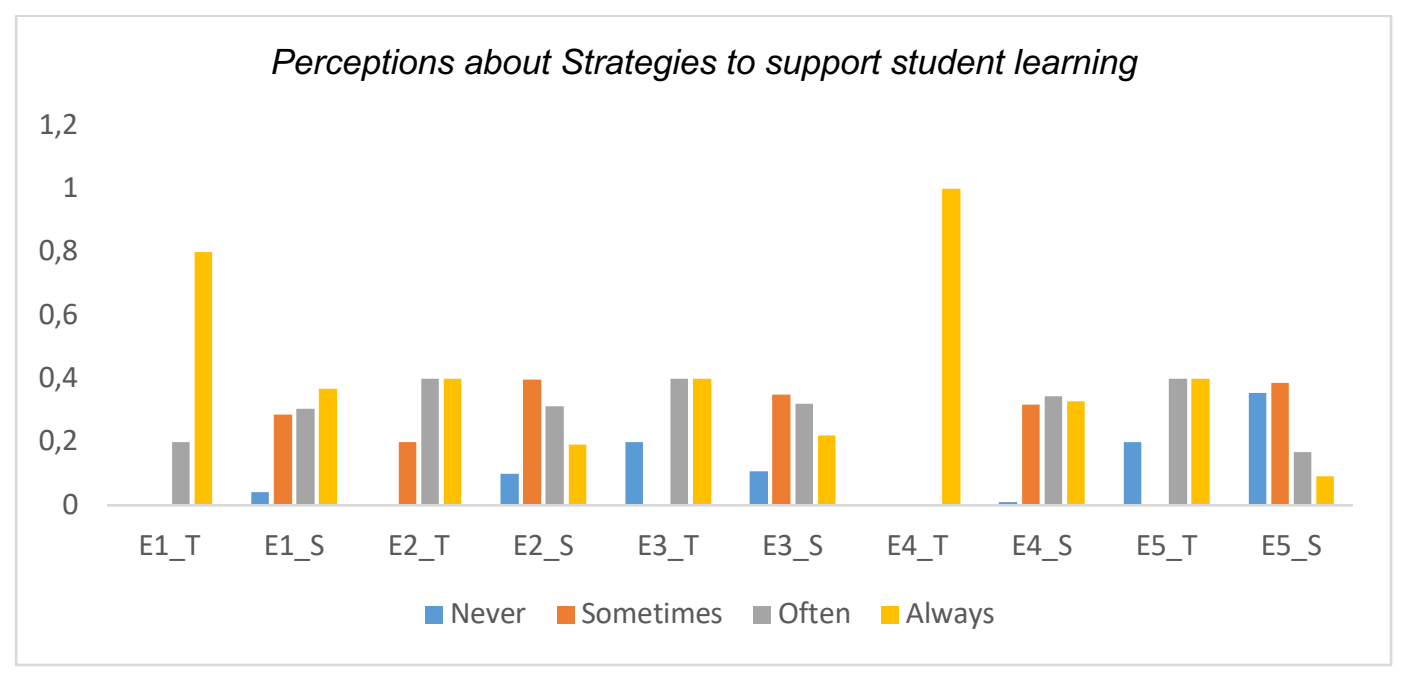

Figure 2. Perceptions of teachers and students about Strategies to support student learning

With regard to the learning assessment, the teachers' perceptions are much more positive than those of the students, as shown in Figure 3. All teachers refer to the answer "always" in the case of the items "Evaluation criteria explained (Av1_T)" and "Use of students' self-assessment in order to make them reflect on their learning (Av4_T)".

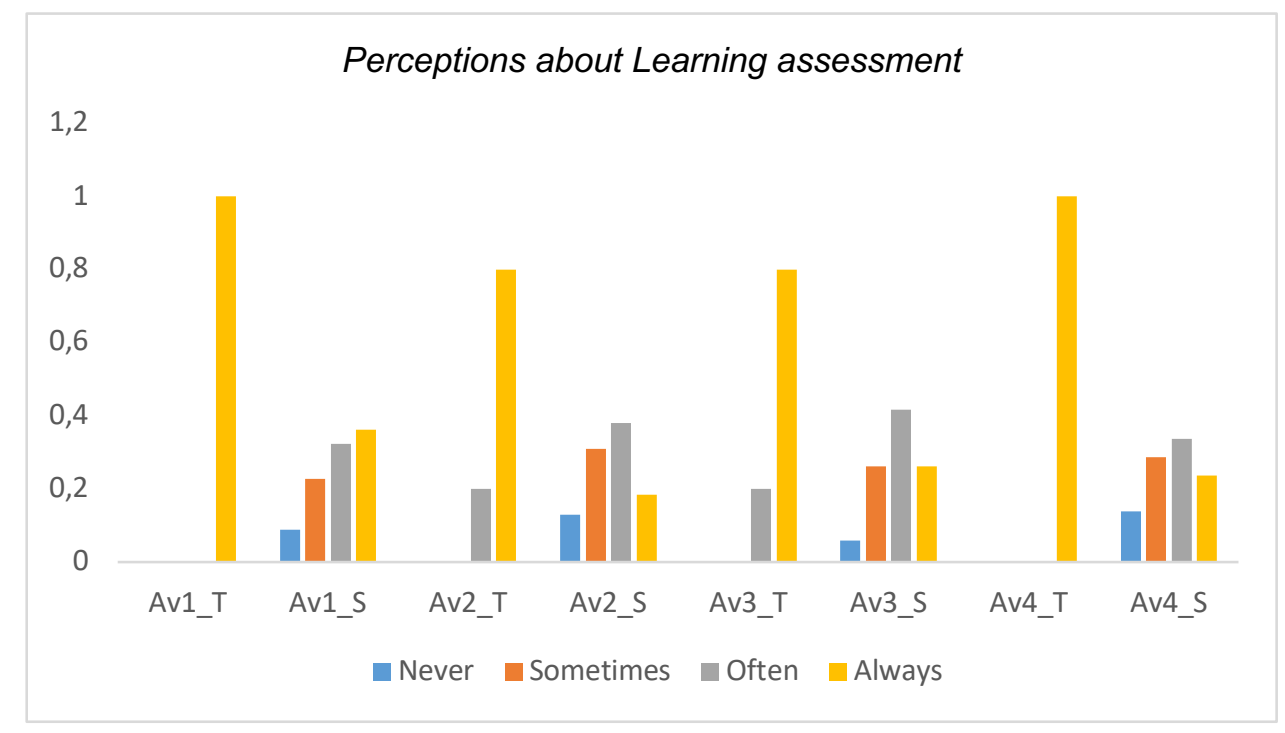

Figure 3. Perceptions of teachers and students about learning assessment

Overall, teachers' perceptions are more positive regarding teaching and learning, in the case of resources and instruments used in the classroom, strategies to support student learning and assessment of learning, compared to those expressed by students. The most positive perceptions of students are those expressed in relation to the items: "Learning is assessed in different ways (Av3_S)", "Clarification of doubts (E4_S)", and "Encourage student participation (E1_S)".

Students express much more diverse opinions, compared to teachers, at the level of items R1 ("Use of diversified resources"), E2 ("Carrying out diversified activities"), E3 ("Encouraging participation in activities and projects that contribute to learning), and E5 ("Carrying out activities involving other disciplines"). However, both parties (teachers and students) have relatively consonant opinions with regard to items E1 ("opportunities to participate in class activities") and Av1 ("explanation of the evaluation criteria").

The proportions referring to the teachers who attributed the highest scores, 3 ("often") or 4 ("always"), to each item under analysis, are always higher, compared to those referring to students, as shown in Figure 4. 
Perceptions (more positive) about teaching and learrning
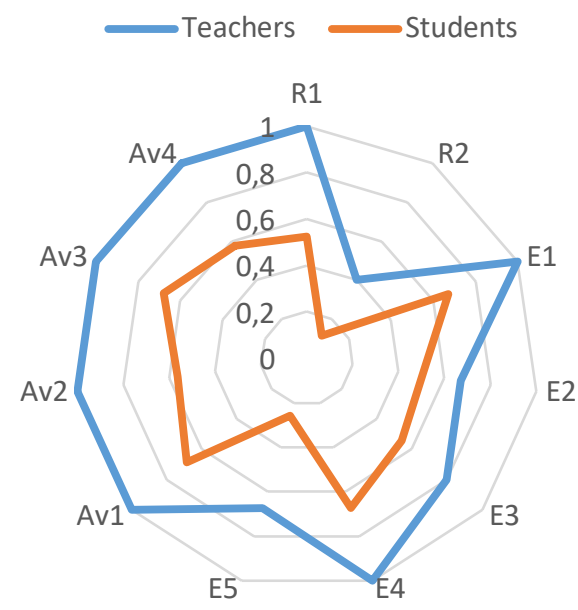

Figure 4. Perceptions of teachers and students about teaching and learning (proportion of individuals that evaluated each item with 3 ("often") or 4 ("always"): Comparison between teachers and students.

In order to verify whether there are significant differences between teachers and students with regard to the proportions shown in Figure 4, the test for the difference of two proportions was carried out. Thereby, we concluded that all observed differences were statistically significant $(p<0.01)$, as shown in Table 1 , with teachers expressing more favorable opinions than students regarding the distance teaching and learning.

Table 1. Results of the hypothesis test for the difference between two proportions

\begin{tabular}{|l|c|c|c|}
\hline Resources and instruments used in the classroom & Proportions* & $\begin{array}{c}\text { Test statistic } \\
(\mathrm{Z})\end{array}$ & $\begin{array}{c}\text { Bilateral test } \\
(p)\end{array}$ \\
\hline R1. I use diverse resources & $\mathrm{p} 1=0.8 ; \mathrm{p} 2=0.525$ & 2.973 & 0.0029 \\
\hline R2. I use the school manual & $\mathrm{p} 1=0.40, \mathrm{p} 2=0.116$ & 4.616 & $<0.0001$ \\
\hline \multicolumn{5}{|l|}{ Strategies to support student learning } & $\mathrm{p} 1=1, \mathrm{p} 2=0.634$ & 4.077 & $<0.0001$ \\
\hline E1. I encourage student participation & $\mathrm{p} 1=0.80, \mathrm{p} 2=0.504$ & 3.1923 & 0.0014 \\
\hline E2. Diversification of classroom activities & $\mathrm{p} 1=0.80, \mathrm{p} 2=0.542$ & 2.8004 & 0.0051 \\
\hline E3. I Encourage student participation in project activities and work & $\mathrm{p} 1=1, \mathrm{p} 2=0.673$ & 3.7908 & 0.0002 \\
\hline E4. Clarification of doubts & $\mathrm{p} 1=0.80, \mathrm{p} 2=0.258$ & 6.5448 & $<0.0001$ \\
\hline E5. I carry out activities / projects that involve other discipline (s) & & \\
\hline Learning assessment & $\mathrm{p} 1=1, \mathrm{p} 2=0.685$ & 3.6851 & 0.0002 \\
\hline Av1. Evaluation criteria explained & $\mathrm{p} 1=1, \mathrm{p} 2=0.563$ & 4.7745 & $<0.0001$ \\
\hline $\begin{array}{l}\text { Av2. I help students to understand their difficulties and how } \\
\text { to overcome them }\end{array}$ & $\mathrm{p} 1=1, \mathrm{p} 2=0.673$ & 3.7379 & 0.0002 \\
\hline Av3. Learning is assessed in different ways & $\mathrm{p} 1=1, \mathrm{p} 2=0.575$ & 4.6571 & $<0.0001$ \\
\hline $\begin{array}{l}\text { Av4. Use of students' self-assessment in order to make } \\
\text { them reflect on their learning }\end{array}$ & & & \\
\hline \hline
\end{tabular}

* p1 - Teachers' proportion; p2- Students' proportion

In order to compare the typologies referring to the items under analysis in both cases (teachers and students), some algorithms of Cluster Analysis were applied on the submatrices that contain the eleven items. 

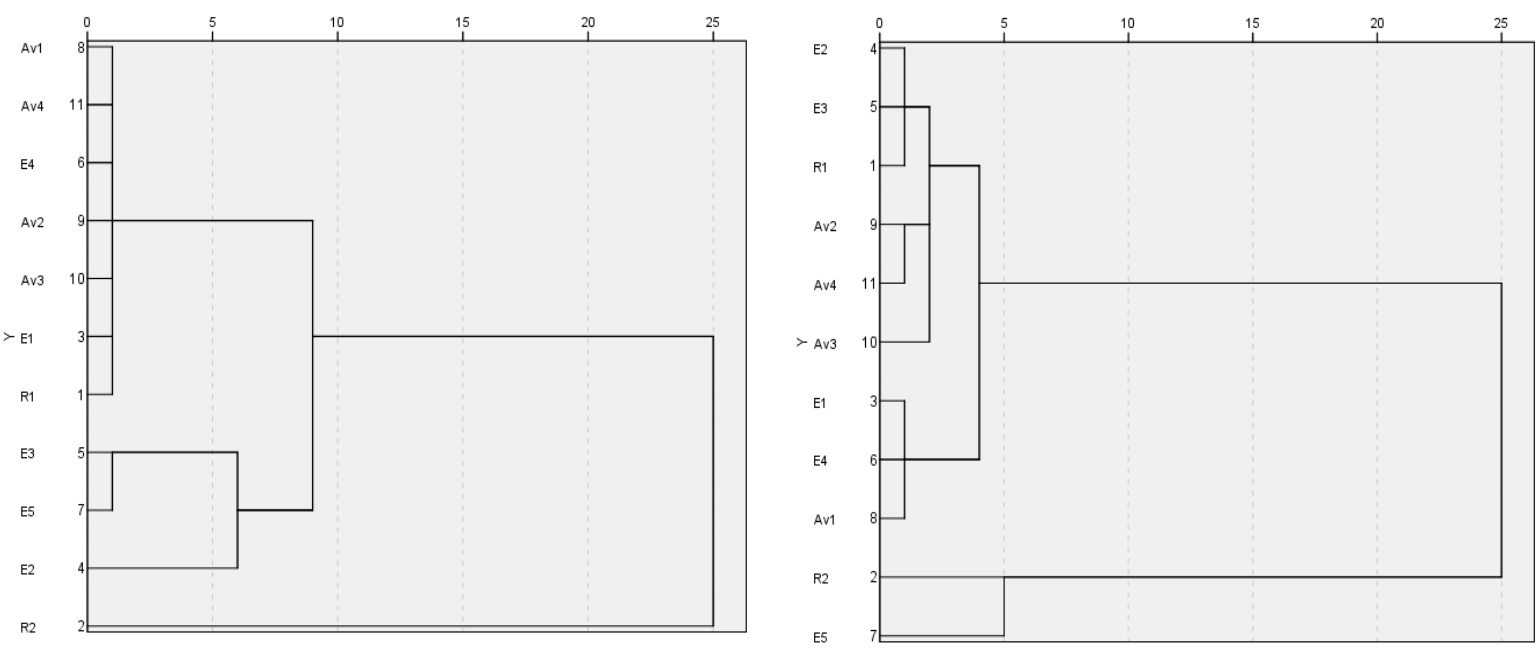

Figure 5. Dendrograms obtained with Average Linkage between groups methodTeachers (on the left) and Students (on the right)

The dendrograms shown in Figure 5 reveal two different typologies, one for teachers (on the left) and another for students (on the right). In the case of teachers, there is a high similarity between the items included in the first cluster, $\{\mathrm{R} 1, \mathrm{E} 1, \mathrm{Av} 2, \mathrm{Av} 3, \mathrm{E} 4, \mathrm{Av} 4, \mathrm{Av} 1\}$, the same is applied to the case of two of the items (E3 and E5) belonging to the second cluster, $\{E 3, E 5, E 2\}$. It should be noted that the item that most deviates from the rest, with regard to the scores attributed by the students, was R2, which is included in the third cluster ( $\{\mathrm{R} 2\})$. On the other hand, in the case of students, greater discrepancies are visible in terms of item evaluation, with three clusters of items standing out: $\{E 2, E 3, R 1, A v 2, A v 4$, $A v 3\} ;\{E 1, E 4, A v 1\}$; and $\{R 2, E 5\}$. Moreover, the second dendrogram also shows that, the items that were the subject of a more consensual evaluation, among students, were the items R1 and E2; Av2 and $\mathrm{Av} 4$; and E1, E4 and Av1. Thus, these two different typologies of items, evidenced by dendrograms, reflect different profiles regarding the perceptions of teachers and students.

\section{CONCLUSIONS}

In this preliminary study, it appears that teachers revealed a more positive perception than students in assessing teaching and learning that took place in this period of social distancing, also called physical distancing, due to the COVID-19. Students revealed more heterogeneous responses and not-sopositive perceptions compared to teachers in the case of all items under assessment. These findings suggest that students may have had some difficulties or that this change did not fully motivate them to apply themselves to their studies. In this period, in the perception of students, there was a very low use of school textbooks and few activities / projects involving other subject (s) were carried out.

Students' participation may have a great influence on the relationship between students' perceptions and academic achievement. Therefore, teachers must be aware of the importance of a learning environment in which students have the opportunity to express their ideas, ask questions, interact with their peers and engage in their own learning. In this context, teachers should try to obtain student's feedback during the teaching and learning process, in order to avoid student disengagement and poor performance. Thus, teachers must take student questions and comments seriously, since class participation and student feedback are two important aspects of student learning. Finally, our findings may help to make teachers aware of the need for new materials, resources and strategies that enhance teaching and learning in an online environment.

\section{ACKNOWLEDGEMENTS}

This work is financed by national funds through FCT - Foundation for Science and Technology, I.P., within the scope of the project «UIDB / 04647/2020» of CICS.NOVA - Centro Interdisciplinar de Ciências Sociais da Universidade Nova de Lisboa. 


\section{REFERENCES}

[1] Martin, A., Dowson, M., "Interpersonal relationships, motivation, engagement, and achievement: Yields for theory, current issues, and educational practice", Review of Educational Research, 79 (1), 327-365, 2009.

[2] Wayne, A., Youngs, P., "Teacher characteristics and student achievement gains: A review", Review of Educational Research, 5, 201-225, 2003.

[3] Norris, J., "Looking at classroom management through a social and emotional learning lens", Theory into practice, 42 (4), 313-318, 2003.

[4] Hattie, J.,Visible learning for teachers: maximizing impact on learning. New York: Routledge, 2012.

[5] Stiggins, R., The perfect assessment system. Alexandria, VA: ASCD, 2017.

[6] Earl, L., Assessment as learning: using classroom assessment to maximize student learning (2nd ed.). Thousand Oaks: Corwin Press, 2013.

[7] Hadar, L., Ergas, O., Alpert, B., Ariav, T., "Rethinking Teacher Education in a VUCA World: Student Teachers' Social-emotional Competencies during the Covid-19 Crisis", European Journal of Teacher Education 1-14, 2020.

[8] Song, L., Singleton, E., Hill, J., Koh, M., "Improving online learning: Student perceptions of useful and challenging characteristics", The Internet and Higher Education, 7(1), 59-70, 2004.

[9] Parkes, M., Stein, S., Reading, C., "Student preparedness for university e-learning environments", The Internet and Higher Education, 25, 1-10, 2014.

[10] Smart, K., Cappel, J., "Students' perceptions of online learning: A comparative study", Journal of Information Technology Education, 5, 201-219, 2006.

[11] Golladay, R., Prybutok, V., Huff, R., "Critical success factors for the online learner", Journal of Computer Information Systems, 40(4), 69-71, 2000.

[12] Serwatka, J., "Assessment in on-line CIS courses", Journal of Computer Information Systems, 43(3), 16-20, 2003.

[13] Reyes, M., Brackett, M., Rivers, S., White, M., Salovey, P., "Classroom emotional climate, student engagement, and academic achievement", Journal of Educational Psychology, 104(3), 700-712, 2012.

[14] Husain, M., Khan, S., "Students' feedback: An effective tool in teachers' evaluation system", International Journal of Applied Basic Medical Research, 6(3):178-81, 2016.

[15] Silva, O., Nunes, J., Sousa, Á., Cabral, J., 'University students' satisfaction with moodle learning management system", ICERI2017 Proceedings: 10th International Conference of Education, Research and Innovation, 8058-8065, IATED Academy. ISBN: 978-84-697-6957-7, 2017.

[16] Lohr, S., Sampling: Design and Analysis, Chapman \& Hall/CRC Texts in Statistical Science, 2nd Edition. Routledge, 2019.

[17] Anderberg, M., Cluster Analysis for Applications, Academic Press: New York, 1973. 